\title{
Multilocus molecular systematics of the circumtropical reef- fish genus Abudefduf (Pomacentridae): history, geography and ecology of speciation
}

\author{
Matthew A Campbell \\ D Ross Robertson \\ ${ }^{1}$ Smithsonian Tropical Research Institute, Balboa, Republic of Panama \\ 2 Western Australian Museum, Welshpool, Western Australia, Australia \\ Corresponding Authors: Matthew A Campbell, D Ross Robertson \\ Email address: DrMacCampbell@gmail.com, drr@stri.org
}

Marta I Vargas ${ }^{1}$

Gerald R Allen ${ }^{2}$

William O McMillan

We investigate a pantropical sub-family and genus of damselfishes, the sergeant-majors (Pomacentridae: Abudefdufinae: Abudefduf), to identify the tempo and mechanisms of speciation in the lineage. We examine sequence capture data from 500 loci and 20 species, with multiple individuals sampled from across the geographic ranges of widespread species. Utilizing a maximum likelihood framework, as well as a timecalibrated Bayesian phylogeny, the following key questions are addressed: What is the historical tempo of speciation? What are the relative contributions of vicariant, peripatric and parapatric speciation to sergeant-major diversity? How is speciation related to major variation in trophic ecology? The approximately 20 species of sergeant-majors fall into three main lineages. The ancestral condition appears to be benthivory, which is predominant in two lineages comprising six species. The remaining species of sergeantmajors, of which there are at least 15 , fall within a clade composed entirely of planktivores. This clade is sister to a benthivore clade that includes a species, $A$. notatus, in transition to planktivory. Most speciation of sergeant-majors, which appeared $\sim 24$ million years ago, occurred in the last 10 million years. Present distributional patterns indicate vicariant speciation precipitated by the closure of land barriers between both sides of the Atlantic and the Pacific, and the emergence of land between the Indian and Pacific Oceans. Within this backdrop, frequent oscillations in sea level over the last 10 million years also appear to have generated conditions suitable for both peripatric and vicariant speciation, and most speciation within the genus appears linked to these changes in sea level. Diversification within the genus has been concentrated in planktivorous seargeant-majors rather than benthivores. The root cause is unclear, but does not appear to be related to differences in dispersal potential, which is greater in the planktivorous species due to the ability of their post-larval juveniles to raft with floating debris. This 
elevated speciation rate in planktivores and their propensity to form local endemics may reflect relaxation of selective pressures (e.g. on crypticity) that limit speciation in benthivorous sergeant-majors. Finally, our data allow us to clarify relationships of geminate sergeant-major species, indicating that there are subdivisions within the Atlantic for both benthivore and planktivore geminate pairs that may have misled previous studies. 
1 Title: Multilocus molecular systematics of the circumtropical reef-fish genus Abudefduf

2 (Pomacentridae): history, geography and ecology of speciation.

3

4 Authors and Affiliations:

5 Matthew A. Campbella, ${ }^{a}$, D. Ross Robertson ${ }^{\mathrm{a}}$, Marta I. Vargas ${ }^{\mathrm{a}}$, Gerald R. Allen ${ }^{\mathrm{b}}$, W. Owen

6 McMillan $^{\mathrm{a}}$

7

8 a Smithsonian Tropical Research Institute, Balboa, Republic of Panama

$9 \quad{ }^{b}$ Western Australian Museum, Welshpool, Western Australia, Australia

10 *Co-Corresponding Author: Matthew A. Campbell, DrMacCampbell@gmail.com

$11 *$ Co-Corresponding Author: D. Ross Roberston, drr@stri.org

12 


\section{Abstract}

14 We investigate a pantropical sub-family and genus of damselfishes, the sergeant-majors

15 (Pomacentridae: Abudefdufinae: Abudefduf), to identify the tempo and mechanisms of speciation

16 in the lineage. We examine sequence capture data from 500 loci and 20 species, with multiple

17 individuals sampled from across the geographic ranges of widespread species. Utilizing a

18 maximum likelihood framework, as well as a time-calibrated Bayesian phylogeny, the following

19 key questions are addressed: What is the historical tempo of speciation? What are the relative

20 contributions of vicariant, peripatric and parapatric speciation to sergeant-major diversity? How

21 is speciation related to major variation in trophic ecology? The approximately 20 species of

22 sergeant-majors fall into three main lineages. The ancestral condition appears to be benthivory,

23 which is predominant in two lineages comprising six species. The remaining species of sergeant-

24 majors, of which there are at least 15 , fall within a clade composed entirely of planktivores. This

25 clade is sister to a benthivore clade that includes a species, A. notatus, in transition to

26 planktivory. Most speciation of sergeant-majors, which appeared $\sim 24$ million years ago, occurred

27 in the last 10 million years. Present distributional patterns indicate vicariant speciation

28 precipitated by the closure of land barriers between both sides of the Atlantic and the Pacific, and

29 the emergence of land between the Indian and Pacific Oceans. Within this backdrop, frequent

30 oscillations in sea level over the last 10 million years also appear to have generated conditions

31 suitable for both peripatric and vicariant speciation, and most speciation within the genus appears

32 linked to these changes in sea level. Diversification within the genus has been concentrated in

33 planktivorous seargeant-majors rather than benthivores. The root cause is unclear, but does not

34 appear to be related to differences in dispersal potential, which is greater in the planktivorous

35 species due to the ability of their post-larval juveniles to raft with floating debris. This elevated 
36 speciation rate in planktivores and their propensity to form local endemics may reflect relaxation

37 of selective pressures (e.g. on crypticity) that limit speciation in benthivorous sergeant-majors.

38 Finally, our data allow us to clarify relationships of geminate sergeant-major species, indicating

39 that there are subdivisions within the Atlantic for both benthivore and planktivore geminate pairs

40 that may have misled previous studies.

41

\section{Keywords}

43 Abudefdufinae; Sergeant-Majors; Isthmus of Panama; Vicariance, Feeding Mode, Phylogenetics 
45

46

47

48

49

50

51

52

53

54

55

56

57

58

59

60

61

62

63

64

65

66

67

\section{Introduction}

Sergeant-majors (Pomacentridae: Abudefdufinae: Abudefduf) are a pantropically distributed genus and subfamily of damselfishes that represent typical members of the fish faunas of coral and rocky reefs in all tropical regions (Cooper et al., 2009). Although the genus has been subject to much recent phylogenetic study, those analyses used few genetic loci and did not include all known species within the genus. As a consequence, uncertainty persists regarding interspecific relationships and how many species of Abudefduf exist (Bertrand et al., 2017; Cooper et al., 2009, 2014; Wibowo et al., 2017).

An early and long-standing hypothesis was that the genus contained two clades with worldwide distributions divided along ecological lines, the $A$. saxatilis clade and the $A$. sordidus clade (Hensley, 1978). The A. saxatilis clade of Hensley (1978) comprised-planktivorous species while the $A$. sordidus clade was made up of benthivorous species. Recent genetic studies indicate that there are in fact three broadly pantropical clades within Abudefduf, (1) an A. saxatilis clade, (2) an $A$. sordidus clade, and, (3) and another clade of benthivores, the A. taurus clade (AguilarMedrano and Barber, 2016; Frédérich et al., 2013). Divisions within the genus along ecological lines revealed in those genetic analyses are broadly in line with Hensley (1978). However, two clades with different feeding ecologies are most closely related to each other, the $A$. saxatilis and A. sordidus clades. Members of the $A$. saxatilis clade have smaller body sizes, live in (often large) aggregations and feed above the bottom in the water column on zooplankton (AguilarMedrano and Barber, 2016; Emery, 1973; Randall, 1967) (See also Range Map 1, 2, \& 3). The pantropical A. saxatilis clade, which is the most species-rich clade, is most closely related to the

67 Indo-Pacific $A$. sordidus clade (Range Map 4). Members of the $A$. sordidus and Atlantic/East 
68 Pacific A. taurus (Range Map 5) clades have thicker, deeper bodies and are benthivores that

69 consume large amounts of benthic algae (Aguilar-Medrano and Barber, 2016; Emery, 1973;

70 Randall, 1967). Members of the A. sordidus clade apparently also consume slightly more animal

71 material that those in the A. taurus clade (Aguilar-Medrano and Barber, 2016).

73 Within both the $A$. saxatilis clade and the $A$. taurus clade, which have alternative ecologies, there 74 are species pairs that were derived from the rise of the Isthmus of Panama. Species originating as 75 a result of vicariance by the closure of the Isthmus of Panama were termed geminates by Jordan 76 (1908). Although some recent studies suggest that the Isthmus formed more than 10 million 77 years ago (MYA), the current general consensus is that the final closure occurred approximately 783 MYA (Coates and Obando, 1996; O’Dea et al., 2016). Geminate species often are morphologically similar and are studied across many taxa to understand molecular evolution (Marko, 2005). Consequently, correctly identifying geminate relationships has important consequences for broader evolutionary research. The two hypothesized geminate species pairs of these fish are A. concolor (East Pacific - EP) and A. taurus (Atlantic - A) (Lessios et al., 1995) in the A. taurus clade, and A. troschelii (EP) and the trans-Atlantic (TA) A. saxatilis in the $A$. saxatilis clade (Bermingham et al., 1997), although more recent work indicates A. troschelii is most closely related to East Atlantic (EA) species A. hoefleri (Frédérich et al. 2013), a relationship similar to that observed in Scarus (Labridae) (Choat et al., 2012).

Despite ongoing and contemporary study of the evolution of sergeant-majors, a fully representative, time-calibrated phylogenetic hypothesis that includes all described species has not yet been produced for the genus (Allen, 1991; Frédérich et al., 2013; Quenouille et al., 2004; 
91 Randall and Earle, 1999). Here, we generate the most comprehensive phylogenetic treatment to

92 date of Abudefduf. In this study we explored sequence variation across approximately 500

93 conserved loci while targeting multiple individuals from each of the 19 currently recognized

94 species. In addition, we generally sample individuals from sites widely scattered across the

95 geographic range of many species. From our sequencing of hundreds of loci we generated a data

96 matrix that produces high-resolution molecular phylogenies not only through providing

97 numerous independent samples of genetic variation from fish genomes, but also by representing

98 many species across Abudefduf with multiple individuals. Such data produce robust molecular

99 phylogenies, both with and without time-calibration, of Abudefduf upon which to test hypotheses

100 about geographical, historical and ecological variation in diversification among lineages. Our

101 results also clarify issues of geminate-species relationships and highlight the need to expand

102 examination for cryptic diversity in the genus with further molecular study.

103

104 Methods

105 Sample Collection

106 We obtained samples from the Smithsonian Tropical Research Institute (STRI) cryocollections at

107 Naos Laboratories, Panama City, Panama and the Natural History Museum, Washington D.C.,

108 U.S.A. Tissues from multiple sampling locations across a wide range of described species were

109 targeted, with successfully sequenced tissues described in Supplemental Table S1. Species

110 involved in possible trans-isthmian geminate species pairs or clades was sampled more heavily

111 (A. troschelii, A. saxatilis, A. hoefleri, A. taurus, and A. concolor) across the widest geographic

112 range for which samples were available. Tissues from the putative geminate species-pair

113 Chromis atrilobata and C. multilineata (Bermingham et al., 1997) were obtained from STRI 
114 cryocollections for further evaluation of the geminate-species concept. We also included

115 Abudefduf luridus, which was recently reclassified as a member of the East Atlantic genus

116 Similiparma (Cooper et al., 2014), to provide representation of an additional divergent

117 pomacentrid lineage. Tissue samples were extracted with Qiagen DNEasy extraction kits

118 (https://www.qiagen.com), electrophoresed for an estimation of quality, and quantified by

119 fluorometric quantitation with a Qubit (Thermo Fisher Scientific Inc.,

120 https://www.thermofisher.com).

121

122 Sequencing

123 We followed the basic procedures outlined for the 500 ultraconserved element (UCE)

124 acanthopterygian probe set by Faircloth et al. (2013). DNA was sheared on a Covaris S2

125 (Covaris Ltd., www.covaris.com) to obtain average fragment sizes between 500 to 600 base pairs

126 (bp). We filtered archived samples for the highest quality DNA; however, because many species

127 did not have alternative tissue samples and were of low fragment size, fragmentation times were

128 adjusted depending on initial sample quality. Illumina DNA sequencing libraries were prepared

129 from fragmented DNA using KAPA library preparation kits (KAPA Biosystems Inc.,

130 www.kapabiosystems.com). Sequence capture was performed by target enrichment (Blumenstiel

131 et al., 2001), incorporating custom adapter blockers with capture probes for 500 loci from

132 actinopterygian fishes (MYbaits_Actinopts-UCE-0.5Kv1, MYcroarray Inc.,

133 www.mycroarray.com). Pre-enrichment PCR length was twelve cycles with post-enrichment

134 PCR of 15 cycles. Eight sample libraries were sequenced on an Illumina MiSeq with paired-end

135 (PE) 300 bp sequencing.

136 
137 Generation of Alignments from Raw Sequence Data

138 Demultiplexed reads were cleaned using Trimmomatic 0.32 (Bolger et al., 2014) driven by the

139 illumiprocessor wrapper script (Faircloth, 2013). A subset samples of cleaned reads were

140 assembled for various kmers with Velvet 1.2.10 (Zerbino and Birney, 2008) to establish a range

141 of suitable kmers for assembly. Due to the heterogeneity of the input DNA and enrichment

142 success, we wrote a custom script to drive VelvetOptimiser 2.2.5 for kmers across overlapping

143 sets of kmers between 95 and 185

144 (https://github.com/MacCampbell/scripts/driveVelvetOptimiser.pl). A final range of kmers

145 (within the span of 95-185) based on the best assemblies indicated by VelvetOptimiser was then

146 applied to each sample and a single optimized assembly retained for further analyses. From here,

147 scripts from the phyluce package were employed (Faircloth et al., 2012; Faircloth, 2014). We

148 filtered samples for overall enrichment and assembly success and aimed to retain at least two

149 samples from each taxon. Description the number of assembled contigs and number of UCEs

150 detected are presented in Supplemental Table S1. We performed sequence alignment with

151 MAFFT 7.130b (Katoh et al., 2002). Four different alignments were generated. First, we

152 included as many samples that enriched and assembled well for Abudefduf species and provided

153 near relatives as outgroups from S. luridus, C. atrilobata and C. multilineata. This "phylogenetic

154 placement" alignment was used to identify distinct lineages, which then informed additional

155 analyses. A second alignment, an "A. saxatilis alignment” focusing on $A$. saxatilis and $A$.

156 hoefleri, was made to increase the number of UCE loci available for analysis to clarify

157 relationships within and between these two species because they were unclear from the

158 phylogenetic placement alignment. A third alignment, the "A. taurus alignment," was generated

159 focusing on the $A$. taurus and $A$. concolor species to increase geographic sampling without 
160 reducing the overall number of loci in the phylogenetic placement alignment. The goal of this

161 alignment was to evaluate phylogeographic divisions within both $A$. taurus and $A$. concolor. A

162 fourth alignment, the "time-calibrated alignment," used a single individual from each unique

163 lineage of Abudefduf identified, a single C. atrilobata, C. multilineata, and S. luridus, and

164 sequences from Faircloth et al., (2013) that were informative for fossil calibration. These

165 additional pomacentrid lineages were chosen in part by overall completeness in terms of number 166 of loci.

Phylogenetic Estimation

169 For analysis of the phylogenetic placement alignment, a maximum likelihood analysis was

170 conducted in RAxML 8.2.6 (Stamatakis, 2014). We partitioned the analysis with PartitionFinder

1712.0 (Lanfear et al., 2012, 2014) by specifying the General Time Reversible (GTR) model with

172 gamma distributed rate variation $(\Gamma)$ to be evaluated across each UCE locus with the "hcluster"

173 search method. The partition supported by a Bayesian Informative Criterion (BIC) selection

174 method was then specified in RAxML with the GTR $+\Gamma$ model of sequence evolution and 1,000

175 rapid bootstrap replicates. Analyses of the $A$. saxatilis alignment and $A$. taurus alignment were

176 conducted with an identical approach to the phylogenetic placement analysis.

178 A time-calibrated phylogenetic tree was generated in a Bayesian framework by importing nexus

179 alignments into BEAUTi 2 and using BEAST 2 to run the BEAUTi output (Bouckaert et al.,

180 2014). Due to uncertainty in the number of independent lineages of $A$. vaigiensis, all samples

181 from this taxon were retained for this analysis. A single partition with a $\mathrm{GTR}+\Gamma$ model of

182 evolution and exponential relaxed clock with a Yule prior were specified. Fossil constraints are 
183 described in Supplemental Table S2. Sufficient effective sample size (ESS $>200)$ was reached

184 by combining eleven chains of 100 million generations with $10 \%$ burnin $(990,110,000$ states).

186 Testing of Diversification Rates

187 Differences in diversification rates (average number of species produced $\mathrm{MY}^{-1}$ ) within the three

188 main Abudefduf lineages were evaluated by reducing the time-calibrated phylogeny from

189 BEAST 2 to independent lineages of Abudefduf. Outgroup species along with repeat sampling of

190 Abudefduf were removed for this analysis. The tree was used as input into BAMMTools

191 (Rabosky et al., 2014) and differences in speciation/extinction rate were tested (modeltype $=$

192 speciationextinction), where an expected number of shifts was set to one. A run length of 1

193 million generations with a $10 \%$ burnin was specified. After the run, ESSs were verified to all be

194 sufficient $(>1,000)$.

195

196 Results

197 Sampling, Sequence Alignment Characteristics, Partitioning

198 We obtained sequence data from all nineteen species of Abudefduf that had been described when

199 the study was initiated. Sample species, collection locality and number of successfully enriched

200 UCE loci are described in Supplementary Table S1. The phylogenetic placement alignment

201 contains 361 UCE loci assembled in 49/59 of samples for a total alignment length of 241,893

202 bases, with 54,757 distinct alignment patterns and $17.93 \%$ missing data including gaps.

203 Partitioning by PartitionFinder indicates twelve partitions (Data Supplement). The A. saxatilis

204 alignment has twelve samples representing A. saxatilis from Sao Tome ( $\mathrm{n}=2)$, A. saxatilis from

205 the West Atlantic $(\mathrm{n}=5)$ and $A$. hoefleri samples from Cape Verde and Senegal $(\mathrm{n}=3)$. Two $A$. 
206 troschelii samples for rooting are also present. Requiring a UCE locus to be present in all

207 samples resulted in ninety-four UCE loci objectively partitioned into two subsets by

208 PartitionFinder (Data Supplement). A total of 59,853 sites, 1,269 distinct alignment patters and

$2098.63 \%$ gaps or missing data characterize the $A$. saxatilis alignment. Focusing on $A$. taurus and $A$.

210 concolor utilizing samples that did not enrich well and were previously excluded from the

211 phylogenetic placement analysis results in a geographic sampling from the Galapagos Islands

$212(\mathrm{n}=3)$, Panama $(\mathrm{n}=2)$ and Costa Rica $(\mathrm{n}=1)$ while including a wide sampling of A. taurus

213 previously included in the phylogenetic placement alignment (Panama $(\mathrm{n}=2)$, Venezuela $(\mathrm{n}=2)$,

214 Cape Verde $(\mathrm{n}=2)$, Sao Tome $(\mathrm{n}=2))$. With the addition of the two A. declivifrons samples, 16

215 samples are present in the $A$. taurus alignment. Permitting one missing sequence per locus allows

$216118 \mathrm{UCE}$ loci for analysis. The total number of sites in this alignment is 78,074 with 3,701

217 distinct alignment patterns and $11.01 \%$ gaps or missing data. The time-calibrated alignment

218 contained 35 taxa and 22 Abudefduf samples and it is characterized by 85,838 sites, 28,506

219 distinct alignment patterns and $22.41 \%$ missing data.

220

221 Molecular Phylogenetics of Abudefduf

222 Both the phylogenetic placement analysis and Bayesian timetree support the existence of three

223 major clades of Abudefduf (Figures 1 \& 2, tree files provided in Data Supplement). An

224 alternative depiction of Figure 1 in which specific sample identifiers are appended to labels in

225 the phylogenetic tree is presented as Supplemental Figure S1. Clade A / "taurus clade" contains

226 A. declivifrons of the Eastern Pacific and the putative geminate species pair A. taurus and A.

227 concolor. The monophyly of the Clade A and placement of species is well supported with

228 bootstrap support $(\mathrm{BS})=100 \%$ and posterior probability $(\mathrm{PP})=1.00$, except for $A$. concolor, 
229 with monophyly supported by $\mathrm{BS}=90 \%(\mathrm{PP}=1.00)$. Clade A is entirely composed of

230 benthivorous species. A second well-supported clade (B / "sordidus clade") contains three Indo-

231 Pacific (IP) species- A. sordidus, A. septemfasciatus, and A. notatus. Support for the monophyly

232 and placement of lineages within clade $\mathrm{B}$ are high $(\mathrm{BS}=100 \%, \mathrm{PP}=1.00)$. Clade $\mathrm{B}$ contains

233 two benthivores, and one species in transition to planktivory (A. notatus). The majority of

234 Abudefduf species belong to the pantropical Clade C ("saxitilis clade"). Monophyly of this clade

235 is well-supported ( $\mathrm{BS}=100 \%, \mathrm{PP}=1.00$ ). Numerous nodes receive moderate to low support in

236 the ML analysis throughout Clade $\mathrm{C}$ and a single node in the Bayesian timetree is supported by a

237 posterior probability of $<1.00$ within Clade C. All Clade C species are planktivores.

238

239 The phylogenetic results indicate the existence of an undescribed species of Abudefduf within

240 Clade C: a sample labelled A. vaigiensis (STRI-x-6065) from Christmas Island (Kiritimati) in the

241 central Pacific (Figures 1 \& 2). A. cf. vaigiensis Kiritimati is most closely related to non- A.

242 vaigiensis samples, and distantly so to A. vaigiensis. The other samples of A. vaigiensis (Red Sea

243 and Australia) are most closely related to each other, although sampled from a great distance

244 apart (Figures 1 and 2, Range Map 1). Within the phylogenetic placement analysis, the

245 relationships among $A$. cf. vaigiensis, A. margariteus, $A$. whitleyi, and (A. bengalensis $+A$.

246 lorenzi) are not clearly resolved, including low support for a sister relationship between $A$.

247 whitleyi and A. cf. vaigiensis $(\mathrm{BS}=55 \%)$. A. bengalensis and A. lorenzi are the closest relatives

248 of $A$. cf. vaigiensis Kiritimati in the Bayesian analysis with high $(\mathrm{PP}=1.00)$ support. Low

249 support for early-branching nodes in Clade C (Figure 1) prevents an unambiguous placement of

250 A. cf. vaigiensis that is clearly supported by both the maximum likelihood and Bayesian 
251 analyses; however, there is support from both analysis frameworks for a close relationship

252 between $A$. cf. vaigiensis and A. bengalensis + A. lorenzi.

253

254 Divergence Time Estimation

255 The median estimate of time to most recent common ancestor (TMRCA) of all Abudefduf species 256 is 24 MYA (95\% Highest Posterior Density (HPD), $11-39$ MYA) (Figure 2 \& Supplemental

257 Figure S2). The median TMRCA of Clade B and C is 15 MYA (95\% HPD 6.7 - 28 MYA).

258 Median TMRCAs for each of the three main clades are Clade A 8.5 MYA (95\% HPD $4.1-20$

259 MYA), Clade B 6.5 MYA (95\% HPD 1.5 - 15 MYA), and Clade C 8.4 MYA (95\% HPD 6.7 -

26028 MYA). TMRCA of the geminate species-pair of A. taurus and A. concolor is 4.0 MYA (95\%

261 HPD 3.5 - 5.5 MYA). The unconstrained TMRCA of the geminate species clade of $A$. troschelii

$262+$ (A. saxatilis, A. hoefleri) is estimated with a median of 2.4 MYA (95\% HPD $0.75-4.9$ MYA)

263 and the TMRCA of East Atlantic and West Atlantic lineages of A. saxatilis $+A$. hoefleri and A.

264 saxatilis respectively is 1.7 MYA (95\% HPD $0.46-3.8$ MYA). The timetree indicates that the

265 putative species $A$. cf. vaigiensis Kiritimati has been independent for approximately 5.6 million

266 years (95\% HPD 1.5 - 12 MYA) while the TMRCA of the Chromis geminate species pair $C$.

267 atrilobata and C. multilineata is 13 MYA (95\% HPD 2.3-32 MYA).

Diversification Rates

270 From the 9,001 posterior samples generated by a total run length of 1,000,000 steps, the ESS of

271 the number of shifts is $1,449.15$ and the ESS of $\log$ (Likelihood) is $3,426.83$. The posterior

272 distribution of shifts in the rate of diversification indicated that there are likely no shifts.

273 Posterior probabilities of rate shifts are zero-rate shifts, 0.90 , one-rate shift 0.08 and two-rate 
274 shifts 0.01 . These results indicate uniform diversification rates within the three lineages of

275 Abudefduf under the framework of BAMMTools. However, the lack of significant differences

276 between rates in those three lineages likely reflects low power of the test due to small sample

277 sizes (cf. Agapow and Purvis, 2002; Kubo and Iwasa, 1995). Despite the results of the test in

278 BAMMTOOLS, there are obvious differences in that rate, which, based on the TMRCAs shown

279 above, is 0.12 species my ${ }^{-1}$ in Clade A (the oldest, benthivore clade), 0.19 species my ${ }^{-1}$ in Clade

280 B (the younger benthivore clade), and 1.13 species my ${ }^{-1}$ in Clade C (the equally young

281 planktivore clade). There are no obvious differences in the tempo of diversification between

282 planktivores and benthivores, as most speciation in both ecotypes occurred during the last 10

283 million years (Figure 2).

284

285 Atlantic-East Pacific Geminate Lineages

286 The phylogenetic analyses indicate that $A$. concolor and A. taurus are a geminate-species pair

287 (Figures $1 \& 2$, Supplemental Figure S3, tree files provided in Data Supplement). As a

288 calibration point in the timetree with a mean divergence time of 3.5 MYA, the posterior estimate

289 of divergence time between the two species was slightly older (4.0 MYA). The widespread

290 sampling of A. taurus; however, did reveal that there is clear geographic structuring across the

291 Atlantic of this benthivore (Figure 1, Supplemental Figure S3). A. taurus segregates into East

292 Atlantic (EA: Sao Tome/Cape Verde) and West Atlantic (WA: Panama/Venezuela) clades (BS =

$293100 \%$ ). The A. taurus alignment of 118 UCE loci (as opposed to 361 UCE loci in the

294 phylogenetic placement alignment) supports the same division into EA and WA clades within $A$.

295 taurus $(\mathrm{BS}=100 \%)$ but does not indicate any geographic subdivisions within $A$. concolor in the

296 East Pacific (EP; Supplemental Figure S3). Therefore, Clade A geminates are A. concolor and 
297 the ancestor of the EA and WA populations of $A$. taurus, which separated long after the closure 298 of the Isthmus of Panama.

299

300 Our phylogenetic analyses also demonstrate that the relationships among A. troschelii, $A$.

301 saxatilis, and A. hoefleri are less straightforward than previously thought. Those analyses

302 indicate that $A$. saxatilis is paraphyletic and that $A$. hoefleri is most closely related to EA $A$.

303 saxatilis (Figures 1 \& 2). Increased sampling of individuals and loci with the $A$. saxatilis

304 alignment (Figure 3, tree file provided in Data Supplement) produces strong support for the

305 paraphyly of $A$. saxatilis with a split between WA A. saxatilis and EA A. saxatilis + A. hoefleri

306 (BS $=100 \%)$, while A. hoefleri monophyly is only weakly supported $(\mathrm{BS}=20 \%)$. A. saxatilis

307 (including $A$. hoefleri), is most closely related to A. troschelii, and forms separate EA (Sao

308 Tome, Cape Verde, Senegal) and WA clades (Panama, Jamaica, Brazil) (Figure 3). Thus EA

309 (Sao Tome) A. saxatilis is most closely related to EA A. hoefleri (Cape Verde and Senegal).

310 Within the West Atlantic, there appears to be no geographic structuring of $A$. saxatilis between

311 the Caribbean and Brazil (cf. Piñeros and Gutiérrez-Rodríguez, 2017). Divergence time estimates

312 for the TMRCA of the geminate-clade of (A. saxatilis WA $($ A. saxatilis $\mathrm{EA}+$ A. hoefleri $))+$ A.

313 troschelii are not constrained by any calibrations and are compatible with the closure of the

314 Isthmus of Panama within the last 5 million years (2.4 MYA, 95\% HPD $0.75-4.9$ MYA). A late

315 closure date for the Isthmus of Panama is widely supported, around 3 MYA (O’Dea et al., 2016).

316 Our data indicate a transatlantic division of the common ancestor of A. saxatilis and A. hoefleri

317 approximately 1.7 MYA (95\% HPD 0.46-3.8 MYA) into WA and EA lineages. Subsequently,

318 within the East Atlantic lineage 0.76 MYA (95\% HPD 0.12-2.2 MYA) A. hoefleri split from EA

319 A. saxatilis. 


\section{Discussion}

322 General Structure of Major Abudefduf Clades

323 Our data set is the most comprehensive phylogenetic treatment to date of sergeant-majors, in

324 terms of species examined, geographic range and number of loci. We targeted 500 UCEs for

325 sequencing from 19 described sergeant-major species, and, after limiting missing data, were able

326 to use 361 loci for phylogenetic inference. In many cases, we sampled individuals from within

327 the same nominal species from multiple geographic locations. Among other things, this resulted

328 in the identification of an undescribed species (A. cf. vaigiensis Kiritimati). The increased

329 taxonomic breath, coupled with the large number of loci, increases the accuracy of our

330 phylogenetic analysis and provides a robust framework for exploring diversification within the

331 group.

332

333 Broadly, our maximum likelihood and time-calibrated trees corroborate previous work on this

334 group by Frédérich et al. (2013), who examined the Pomacentridae as a whole and used in part

335 previously published DNA sequence data. We identified three major clades (A, B, and C)

336 (Figures 1 \& 2), relationships among them agree in both studies with the overall arrangement of

337 major clades being $(\mathrm{A}(\mathrm{B}, \mathrm{C}))$ and the divergence times of major clades are comparable to those of

338 Frédérich et al. (2013) as well. However, relationships we found within Clade C, the most

339 species-rich lineage, differ from some of those of Frédérich et al. (2013). These differences are

340 related to the additional species we examined, the geographic range of our sampling and perhaps

341 due to an increased number of variable sites. Greater representation of species within Abudefduf

342 Clade C with substantially more loci in our study (up to 361 here versus four for Frédérich et al. 
343 2013) not only changed relationships among some clade members, but, more importantly,

344 allowed examination of the tempo of diversification within each of the three major lineages of

345 the genus.

346

347 Paraphyly in Abudefduf vaigiensis

348 Recently, genetic variation of mitochondrial and two nuclear loci was examined across much of

349 the geographic range of $A$. sexfasciatus and A. vaigiensis by Bertrand et al. (2017). That study

350 identified four highly distinct $A$. vaigiensis lineages, which did not form a monophyletic group

351 relative to other closely related species those authors examined. Bertrand et al. (2017) attributed

352 this pattern to widespread, albeit rare, hybridization among species and the presence of a number

353 of cryptic species within A. vaigiensis. Although we sampled far fewer individuals from fewer

354 locations, there are strong indications that $A$. vaigiensis is indeed paraphyletic and is composed

355 of several distinct lineages.

356

357 Our dataset resolves an issue about one of the four A. vaigiensis clades examined by Bertrand et

358 al. (2017), the identity of an "A. vaigiensis" specimen from Kiritimati (STRI-X-6064;

359 cytochrome b sequence AY208557). The Bertrand et al. (2017) study indicated that this

360 individual fell on a distinct lineage sister to $A$. bengalensis, but with weak support (BS $<50 \%$ ).

361 We assembled a partial mitochondrial genome from our Kiritimati specimen of A. cf. vaigiensis

362 (STRI-X-6065) and this individual possessed an identical mtDNA haplotype across 1141 base

363 pairs of cytochrome $b$ to the STRI-X-6064 sequence in the NCBI nucleotide collection database.

364 Our phylogeny clearly indicates this individual is only distantly related to the lineage of $A$.

365 vaigiensis for which we have samples (see below). Nonetheless, a photo of $A$. cf. vaigiensis taken 
366 at Kiritimati (see Figure 1) shows that the color pattern of five black bars on a pale body and pale

367 fins is more similar to that of $A$. vaigiensis than that of $A$. bengalensis, or other potential near

368 relatives (Figure 1). This discrepancy between color pattern and phylogenetic placement may

369 reflect similar patterns having evolved independently in this lineage or the "vaigiensis"-like

370 pattern being ancestral. The color pattern of $A$. cf. vaigiensis also is similar to that of $A$.

371 conformis (Figure 1), which is endemic to the isolated Marquesas Islands (Range Map 1), and

372 not likely to also occur in Kiritimati, $\sim 2,200 \mathrm{~km}$ away. For these reasons, and the fact that $A$.

373 vaigiensis has been recorded in the central Pacific (Range Map 1), DRR labeled the specimens

374 which he collected at Kiritimati in 1996 (STRI-X-6064 and STRI-X-6065) as A. vaigiensis. The

375 mitochondrial phylogeny of Betrand et al. (2017) and phylogenies in this paper from nuclear

376 gene sequence data both indicate that $A$. $c f$. vaigiensis Kiritimati is a distinct species.

377

378 Unfortunately, all the remainder of our wide geographic sampling of $A$. vaigiensis occurred in

379 the area occupied only by $A$. vaigiensis lineage "A" of Bertrand et al. (2017). Fragmentary

380 cytochrome b data from STRI-X-1443 and STRI-X-1497 are greater than $99 \%$ similar to the $A$.

381 vaigiensis reference mitochondrial genome AP006016 and A. vaigiensis A sequences from

382 Bertrand et al. (2017). Thus, based on the partial mitochondrial genome data from our

383 assemblies, we lack samples corresponding to $A$. vaigiensis lineages B and C of Bertrand et al.

384 (2017). Recently, A. caudobimaculatus, Okada and Ikeda 1939, was resurrected from synonymy

385 with $A$. vaigiensis (Allen, 1991) by Wibowo et al., (2017), on the basis of morphological

386 variation, including relatively minor differences in its color pattern. While no genetic data were

387 examined in that study, the geographic distribution of $A$. caudobimaculatus corresponds most

388 closely to that of A. vaigiensis-lineage B of Bertrand et al., (2017). Bertrand et al. (2017, Figure 
389 2), also provide some support for the notion that their lineages $A$ and $C$ represent two other

390 cryptic species within the $A$. vaigiensis clade. Overall, the emerging data indicate that $A$.

391 vaigiensis actually comprises three species (not including the unrelated species from Kiritimati)

392 with largely allopatric distributions. If substantiated, the division of $A$. vaigiensis into additional

393 species would increase the number of localized endemics in planktivore Clade C.

395 Relationships of, and Paraphyly in A. sexfasciatus

396 Our inclusion of the local-endemics, A. natalensis and A. conformis, which were not represented

397 in Bertrand et al. (2017), alters the placement of $A$. sexfasciatus to be most closely related to $A$.

398 natalensis with high support, which is consistent with Hensley and Randall's (1983) discussion

399 of morphological similarities between them. Our study also indicates that A. vaigiensis "A" of

400 Bertrand et al. (2017) is most closely related to A. conformis. Through wide sampling of $A$.

401 sexfasciatus, Bertrand et al. (2017) identified shallow subdivisions between the Indian Ocean,

402 Coral Triangle and Western Pacific; as well as the genetic distinctiveness of more peripheral

403 populations. These geographic divisions provide further evidence for the propensity of

404 planktivores to form genetically isolated populations that ultimately may lead to the formation of

405 new species. Our sampling of $A$. sexfasciatus was limited to two adjacent sites within the Coral

406 Triangle of Bertrand et al. (2017) and is too limited to provide any further insight into this

407 question.

408

409 Atlantic-East Pacific Geminate Lineages

410 Our examination of the benthivorous Clade A indicates that $A$. taurus is divided into WA and EA

411 populations that represent divergent allopatric populations or (perhaps) cryptic species. No 
412 phylogeographic subdivisions were evident in the EP A. concolor, where distances isolating

413 sampled populations are much smaller than separating EA and WA (see Range Map 5 and

414 Supplemental Figure S3). The A. concolor and A. taurus geminate pair arose when the closure of

415 the Isthmus of Panama divided their common ancestor. Subsequently the common ancestor of $A$.

416 taurus lineages divided into EA and WA A. taurus populations (or species).

417

418 The geminate species relationship involving $A$. saxatilis (EA and WA), A. hoefleri (EA), and $A$.

419 troschelii (EP) are clarified here. Rather than A. troschellii and A. hoefleri being sisters (see

420 Frédérich et al. 2013), our analyses indicate that the sister of $A$. troschelii is the ancestor of an

421 Atlantic "species" that now comprises $A$. saxatilis and A. hoefleri, and in which the EA $A$.

422 saxatilis is more closely related to the EA A. hoefleri than to WA A. saxatilis. The

423 phylogeographic pattern reported by (Frédérich et al., 2013) resulted from of a lack of separate

424 EA and WA A. saxatilis representatives in their dataset, and the use of fewer loci (largely

425 GenBank derived super-matrix). Support values for monophyly in the A. troschelii + (A. hoefleri

$426+$ A. saxatilis) geminate clade is not strong in our study $(\mathrm{BS}=65 \%, \mathrm{PP}=1.00)$, which perhaps

427 reflects underlying challenges to identifying these three species as a clade with a molecular

428 phylogenetic framework. Monophyly of $A$. hoefleri was only supported, but weakly so, by using

429 many UCEs (59,853 characters in alignment), while $A$. saxatilis is paraphyletic in both our

430 phylogenetic placement and A. saxatilis alignment analyses. Analysis of genetic variation across

431 the WA range of $A$. saxatilis indicated a lack of genetic structuring in either mtDNA or

432 microsatellites within the Caribbean, and a break between the Caribbean and Brazil populations

433 of $A$. saxatilis in microsatellite data, but not mtDNA data (Piñeros and Gutiérrez-Rodríguez,

434 2017). Our A. saxatilis alignment-phylogenetic-analysis (Figure 3) indicates strong support for 
435 WA monophyly, and a lack of phylogenetic structure within that area. Our estimate of the

436 TMRCA of the A. troschelii + (A. saxatilis, A. hoefleri) geminate clade is very recent, 2.4 MYA

437 (95\% HPD $0.75-4.9$ MYA). Given the capability for long distance gene flow via rafting in $A$.

438 saxatilis (Luiz et al., 2012; Piñeros and Gutiérrez-Rodríguez, 2017), a population genetics

439 analysis that includes both sides of the Atlantic and the mid-Atlantic islands and that examines

440 these three species as a geminate clade would be useful for demonstrating the extent of gene flow

441 and isolation among them.

442

443 Lifestyle Transitions and Diversification Rates

444 Except for A. notatus, all species in both Clades A (taurus) and B (sordidus) are benthic-feeding

445 herbivores that are characterized by large body size, chunky bodies and blunt fins (Aguilar-

446 Medrano and Barber, 2016). They also have uniformly dark brownish bodies and unpaired fins

447 with indistinct pale vertical bars on the body (Figure 1). Clade $\mathrm{C}$ comprises planktivorous fishes

448 that feed in the water column near the surface and that have more slender bodies and longer,

449 more pointed fins than the benthivores (Aguilar-Medrano and Barber, 2016). Species in Clade C

450 have more conspicuous and variable color patterns that often are essentially the reverse of the

451 benthivore pattern, with pale, silvery to silvery-yellow bodies and strong dark vertical bars

452 (Figure 1). Other planktivores have pale bodies with indistinct dark bars, while some lack dark

453 bars and have large blotches of dark pigment, and others have black stripes along the upper and

454 lower edges of the caudal fin. A. notatus, a member of Clade $\mathrm{B}$, is intermediate in its trophic

455 ecology between benthivores and planktivores (Masuda and Allen, 1993) and, like planktivores

456 of Clade C, occurs in (sometimes large) aggregations that feed on plankton in midwater (see:

457 https://www.peerintoyourworld.com/species/pomacentridae/abudefduf-notatus-yellowtail- 
458 sergeant/, accessed January 12, 2018). This species, which evidently is in transition from

459 benthivory to planktivory, the second such a transition within Abudefduf, also has a color pattern

460 intermediate between that of benthivores and planktivores (see Figure 1).

461

462 Statistical testing with BAMMTools to determine whether diversification rates among the three

463 Abudefduf lineages were different was inconclusive. The relatively small number of species in

464 our dataset results contributes to low power which is typical of tests of this type (Agapow and

465 Purvis, 2002; Kubo and Iwasa, 1995). The use of BAMMTools to accurately detect rate variation

466 also has been questioned (Moore et al., 2016; Rabosky et al., 2017) In general, being able to

467 assert that a key innovation is causing increased diversification is problematic (de Queiroz, 2002)

468 and variation in the numbers of extant species in different clades of the same age can, for

469 example, be produced by random speciation and extinction events (Gould et al., 1977; Raup et

470 al., 1973; Slowinski, 1990).

471

472 Nevertheless, Clade $\mathrm{C}$ contains more than twice as many planktivores as there are benthivores in

473 Clades A and B combined ( $>17$ versus six), and 4-8 times the number of benthivores in either of

474 those two clades. Furthermore, although Clade A is distinctly older than clade C (Figure 2), the

475 diversification rate is notably higher in Clade $\mathrm{C}$ than either Clades A and B: 0.12 species $\mathrm{MY}^{-1}$ in

476 Clade A, and 0.19 species $\mathrm{MY}^{-1}$ in Clade B ( 0.13 if $A$. notatus is excluded), versus 1.13 species

$477 \mathrm{MY}^{-1}$ in Clade C. There is an important caveat to this conclusion, that our geographically limited

478 sampling regime may have underestimated the number of species in Clade B. For widespread

479 species, widespread sampling is important, as indicated by our capture of only one of the three

480 major lineages known to exist in A. vaigiensis (plus the undescribed species from Kiritimati). 
481 One of those three lineages has recently been shown to be morphologically distinct (Wibowo et

482 al., 2017) and needs to be genetically assessed. In our study, we relied on prior knowledge of the

483 existence of various named and morphologically distinct species, leading to much more

484 geographically dispersed sampling of Clade C. In contrast, our sampling of one of the

485 benthivorous clades, which lack obvious morphological differences, was geographically much

486 more restricted. Clade A was sampled effectively across its range. However, that is not the case

487 for clade B, in which we used only samples from a single location for both A. septemfasciatus

488 and $A$. notatus, which have large Indo-Central Pacific and Indo-West Pacific ranges,

489 respectively. Thus, we certainly missed any differentiation that might exist across the ranges of

490 these two species. However, our sampling of populations of $A$. sordidus at two central Pacific

491 sites 3,300 km apart, and the Red Sea, 15,000 km from either of those on the opposite side of

492 that species' range, produced levels of divergence similar to those within many others of the

493 species we sampled (Figure 1, Supplemental Figure S4). One of those sites (Johnston Island) is a

494 location where a local-endemic planktivore (A. abdominalis) lives (Randall, 2007). To help

495 overcome these limitations in our sampling of $A$. sordidus and A. septemfasciatus we examined

496 existing mitochondrial data on those species in GenBank merged with mitochondrial sequence

497 data generated as a by-product of sequence capture with samples in this study. That dataset is

498 much more extensive in terms of its geographic coverage for both species. Analysis of

499 mitochondrial data from A. sordidus and A. septemfasciatus (Appendix 1) also indicates that

500 each species represents a single widespread, Indo-central Pacific species rather an aggregate of

501 multiple allopatric species that include local endemics. Similarly divergence of $A$. taurus across

502 the Atlantic is relatively small, and less than that within many other species. Moreover, unlike

503 the situation among members of Clade $\mathrm{C}$, (minor) morphological differences between local 
504 endemics has been described in only one case among Clades A and B species (A. declivifrons vs

505 A. concolor: Lessios et al. 1995).

506

507 With caveats in mind, the higher number of species within Clade $\mathrm{C}$ remains striking and suggests

508 an increase in speciation rate associated with a transition to planktivory. Herbivorous fishes were

509 instrumental in the creation of modern coral reefs, and have occupied coral reefs for at least the

510 last 50 my (Bellwood, 1996, 2003). High availability of planktonic food resulting from increased

511 coastal upwelling is a more recent phenomenon, starting in the Late Miocene ( $\sim 10$ mya) and has

512 been linked to other species radiations (Jacobs et al., 2004). Transitions from benthivory to

513 planktivory are widespread across reef fishes (Floeter et al., 2018; Tavera et al., 2018), and have

514 occurred rapidly in various damselfishes (Cooper and Westneat, 2009). Our results are consistent

515 with the general trend across perciform fishes, in which herbivorous lineages show lower levels

516 of diversification relative to the more recently derived and species-rich invertebrate feeders (see

517 also Clements et al., 2004; Gomon and Paxton, 1985).

518

519 We propose the hypothesis that, in Abudefduf, transitions to planktivory and increased

520 diversification among planktivores may be due to a combination of (i) trophic niches for

521 benthivores generally being pre-occupied by other damselfishes that successfully defend a

522 predictable resource against heterospecifics, and (ii) zooplankton being a high-quality, easily

523 digestible food that is less predictably available and, hence, economically less controllable by

524 species already resident on reefs when the transition to planktivory began in Abudefduf.

525 Speciation among benthivorous Abudefduf may have been limited by competition from the

526 stegastinine damselfishes, which are common on reefs worldwide and which have many species 
527 that defend benthic algal resources. The TMRCA of Stegastinae predates the origin of

528 Abudefdufinae by approximately 20 my (Frédérich et al., 2013). Consequently, prior occupancy

529 of benthivorous niches by stegastinine fishes may have reduced the ability of Abudefduf species

530 to diversify into that ecological role (Lobato et al., 2014). Observations by DRR on both sides of

531 the Isthmus of Panama show that A. taurus and A. concolor live in intertidal and upper subtidal

532 areas, above the zones occupied by dense, multispecies assemblages of benthic-feeding

533 stegastinine damselfishes (species of Microspathodon and Stegastes) (see also information on

534 depth ranges those two Abudefduf species in their IUCN Red List reports:

535 http://www.iucnredlist.org). A. sordidus and A. septemfasciatus in the Indo-Pacific also have

536 similarly narrow, very shallow depth-ranges (Allen 1991). Benthivorous Abudefduf species may

537 have not only few available niches to diversify into, but also sufficient gene flow to counteract

538 any neutral divergence may occur even across large spatial scales in these species.

540 The Tempo of Diversification

541 Although Clade $\mathrm{C}$ is the most species-rich, all three clades of Abudefduf increased in speciation

542 rate during the last $10 \mathrm{MY}$ (Figure 2). This increase may be linked to sea level changes. Since the

543 Late Miocene (i.e. 10 MYA) sea level has trended downwards and become more variable than

544 during the previous history of Abudeduf, when it was more stable and higher than currently exists

545 (Miller, 2009). The start of diversification of Clade C coincides with the onset of this

546 environmental change. An association between increased speciation and sea-level changes has

547 previously been noted in other reef fishes (e.g. Ludt and Rocha, 2015; McCafferty et al., 2002;

548 McMillan and Palumbi, 1995). The creation of numerous islands/reefs to which dispersal and

549 then speciation occurred (peripatric speciation), isolation across the Sahul and Sunda shelves as 
550 they were exposed (allopatric speciation) or isolation due to reduction and fragmentation of

551 coastal habitat and populations during low sea level stands (allopatric speciation) may be the

552 underlying mechanisms of this diversification. Thus, the diversification of the plantivores in

553 Clade C may be driven both by the switching to a different food source, and the sea level

554 oscillations that separated populations.

555

556

\section{Local Endemism}

557 Both planktivorous and benthivorous Abudefduf are pantropical and have broadly overlapping

558 distributions; however, there is a discrepancy in the level of local endemism between these two

559 trophic guilds. Nine of 16 named (and one unnamed) planktivorous species are local endemics,

560 which occur in the Central Pacific (A. abdominalis, A. conformis, A. cf. vaigiensis; Range Map 1

561 \& 3), East Pacific (A. troschelii), East Atlantic (A. hoefleri, Range Map 1), Southwest Pacific (A.

562 whitleyi, Range Map 2), and Southwestern Indian Ocean (SWIO; A. natalensis, A. sparoides, and

563 A. margariteus; Range Map 2 \& 3). In contrast, only two of six named species in either

564 benthivorous clade of Abudefduf clearly are local endemics: A declivifrons and A. concolor,

565 which occupy partly overlapping sections of the EP (Range Map 5). The relatively few species in

566 Abudefduf, particularly in each of the benthivorous clades, makes it difficult to test statistically

567 for differences in levels of regional endemism between trophic guilds and clades. It does appear

568 that the relative proportion of local-endemic benthivores (0.33) is less than that of local-endemic

569 planktivores (0.56); however, a $X^{2}$ test of these proportions is not significant. If these differences

570 are real, what biological properties could lead to the abundance of local-endemic planktivores? 
572 Dispersal ability can be a key factor affecting genetic differentiation between populations of

573 some marine species (Bohonak, 1999; Slatkin, 1987). Here this raises the question - is increased

574 speciation and the creation of local endemics related to a lower dispersal ability in planktivores

575 (compared to benthivores)? The great majority of coral reef fishes have a pelagic larval stage, the

576 duration of which varies between species (Sale, 1980), and has led to the expectation that range

577 size would be positively related to the duration of the pelagic larval duration (PLD). However, a

578 general relationship to that effect has not been found among tropical reef fishes (Lester and

579 Ruttenberg, 2005). Further, species of Abudefduf examined to date have comparatively short

580 PLDs, which should generally limit dispersal potential, and there is little evidence of a consistent

581 difference in PLDs between planktivorous and benthivorous species (Luiz et al., 2012). Range-

582 size in tropical reef fishes evidently is affected by a suite of characters other than PLD, including

583 the ability of post-larval stages to raft on flotsam, as well as adult-biology characteristics that

584 help establishment following dispersal (Jokiel, 1990; Lester et al., 2007; Luiz et al., 2013, 2012).

585 Post-larval juveniles and even adults of planktivorous, but not benthivorous, Abudefduf

586 frequently associate with flotsam (Hunter and Mitchell, 1967; Kimura et al., 1998; Nakata et al.,

587 1988, Luiz et al., 2013, 2012).

588

589 Overlaps in the geographic ranges of sister taxa of planktivorous Abudefduf species that include 590 both widespread species and local endemics, e.g. between A. saxatilis and A. hoefleri in the East

591 Atlantic (Figures $1 \&$ 2, and Range Map 1) and between A. natalensis, A. sparoides and A.

592 sexfasciatus in the Southwest Indian Ocean (Figures $1 \&$ 2, and Range Maps 2 \& 3) clearly

593 demonstrate how widespread planktivores have dispersal powers that enable them to repeatedly

594 colonize sites where they previously evolved into local endemics. Differences in dispersal 
595 characteristics of planktivorous and benthivorous Abudefduf species indicate that planktivores

596 have greater dispersal capabilities, and hence should have larger ranges, greater connectivity and

597 fewer local endemics. This is the reverse of what is observed.

598

599 If not dispersal ability, then what may explain the difference in endemism levels between

600 planktivores and benthivores? The general appearance of benthivores and planktivores is

601 strikingly different (Figure 1) and may provide insight into this question. Benthivorous

602 Abudefduf are very similar in morphology and color, remarkably so in some cases (Lessios et al.,

603 1995), suggesting restrictions on the variation that can be exhibited in such species. Cryptic

604 coloration may be sufficiently important for shallow-living benthivores to constrain color

605 variation among them. Planktivorous Abudefduf, in contrast, are less cryptically colored than the

606 benthivores and also show much more interspecific variation in color patterns, including among

607 local endemics (Figure 1). This variation may be the key factor indicating how differences in

608 diversity between benthivores and planktivores evolved. Small isolated populations often

609 develop odd color forms (e.g. Feitoza et al., 2003), and fixation of color variation may occur

610 very early in the speciation process, promoting the rapid development of allopatric color variants

611 (e.g. Gaither et al., 2014). One well-studied example highlights the importance of color variation

612 in speciation. The Caribbean hamlets (Serranidae: Hypoplectrus) contain many species that vary

613 only in color, and often share the same reef (Fischer, 1980; Holt et al., 2008; Mccartney et al.,

614 2003; Puebla et al., 2007, 2014; Whiteman et al., 2007). Color is of paramount importance for

615 hamlets as the vast majority of matings are between individuals of the same color (Barreto and

616 McCartney, 2008; Fischer, 1980; Puebla et al., 2007), and both natural and sexual selection can

617 act to generate assortative mating that will in turn lead to reproductive isolation and speciation 
618 even with gene flow (Puebla et al., 2012).-Presence of color-assortative mating in

619 Chaetodontidae (McMillan et al., 1999), Serranidae (see references above) and Cirrhitidae

620 (Whitney et al., 2018) indicates that the process is generally distributed among reef fishes.

621 Hence, the idea that within planktivorous Abudefduf, an ability to vary color may have promoted

622 assortative color-based mating that facilitate speciation and the creation of regional endemics is

623 not unreasonable.

624

625 Conclusions

626 Two of the three major clades of Abudefduf (Clades A and B) are primarily benthivores,

627 apparently have few regional endemics, and many of their few species are widely distributed. In

628 contrast, Clade $\mathrm{C}$ comprises planktivores and includes both wide-ranging species and a higher

629 proportion of regional endemics. Past instability in sea level over the last 10 MYA appears to be

630 linked to increased recent speciation in all three clades.

631

632 Paradoxically, there are $\sim$ three times as many species of planktivores in a single clade as

633 benthivores in two well-separated clades. Although neither differences in diversification rates

634 nor the relative abundance of local endemics were statistically different between clades or

635 trophic guilds of Abudefduf, this likely reflects small sample sizes. This pattern exists even

636 though dispersal by planktivores through flotsam-rafting (Luiz et al., 2012, 2013) may lead to

637 higher dispersal rates likely to promote gene flow and reduce isolation. Benthivorous Abudefduf

638 species, in contrast, are not known to participate in flotsam dispersal. Despite the wide, Indo-

639 central Pacific ranges of some benthivores, i.e. A. sordidus and A. septemfasciatus, they do not

640 appear to have produced local endemics, or at least local endemics with distinctive color 
641 patterns. Thus a large question remains open in Abudefduf, why do planktivores, with greater

642 dispersal powers, have a much stronger tendency than benthivores to produce morphologically

643 distinct local endemics? In another genus of damselfishes it has been proposed that biological

644 factors such as ecological pressures and sexual selection can generate new species even when

645 dispersal barriers are absent (Leray et al., 2010). We suggest that an ability of planktivores to

646 vary in morphology and color facilitates assortative mating that leads to speciation, while natural

647 selection for crypticity constrains coloration of benthivores, and restricts speciation through

648 assortative mating.

649

650 Future Research Directions

651 To test our hypothesis that planktivorous Abudefduf have a greater capacity to diversify and

652 form local endemics than do benthivorous congeners a multilocus analysis based on broad

653 geographic sampling is needed for all Clade B species throughout their large Indo-central Pacific

654 ranges, particularly at sites occupied by local-endemic planktivores. That will demonstrate the

655 extent to which benthivores represent broadly distributed species versus collections of allopatric

656 cryptic species. Further sampling of broadly distributed planktivores in the Indo-central Pacific

657 (A. sexfasciatus and A. vaigiensis) and parts of the Atlantic (A. saxatilis) also are necessary to

658 clarify the extent to which they constitute a collection of local endemics. In addition, detailed

659 information on the trophic and community ecology of all benthivores is needed to understand

660 how they fit into speciose assemblages of benthivorous damselfishes, many of which

661 aggressively control benthic resources and arose long before Abudefduf evolved.

662

663 Acknowledgements 
664 We thank staff of the Smithsonian Tropical Research Institute who assisted the research - Maria

665 Fernanda Castillo, Ruth Reina, Wayra Navia and Eyda Gomez. This research came out of a 666 workshop organized by Matthew J. Miller and run by Noor White and Brant Faircloth at the 667 Smithsonian Tropical Research Institute. MAC would like to acknowledge Jose Loaiza, Justin 668 Touchon, Carlos Arias and Fernando Alda for their assistance and companionship during his 669 time at the Smithsonian Tropical Research Institute and Kerry Reid for helpful discussions 670 during the preparation of the manuscript. We appreciate access to tissue samples from the Naos

671 Island Laboratories cryocollections at the Smithsonian Tropical Research Institute and the 672 Smithsonian Institution National Museum of Natural History. We would also like to thank Sergio 673 Floeter, Jack Randall and John Earl for granting us permission to use their photos in the 674 manuscript. 


\section{Bibliography}

676 Agapow, P.-M., Purvis, A., 2002. Power of eight tree shape statistics to detect nonrandom

677 diversification: a comparison by simulation of two models of cladogenesis. Syst. Biol. 51,

678 866-872. https://doi.org/10.1080/10635150290102564

679 Aguilar-Medrano, R., Barber, P.H., 2016. Ecomorphological diversification in reef fish of the 680 genus Abudefduf(Percifomes, Pomacentridae). Zoomorphology 135, 103-114.

681 https://doi.org/10.1007/s00435-015-0291-6

682 Allen, G.R., 1991. Damselfishes of the world. Mergus, Melle.

683 Barreto, F.S., McCartney, M.A., 2008. Extraordinary AFLP fingerprint similarity despite strong 684 assortative mating between reef fish color morphospecies. Evolution 62, 226-233.

$685 \quad$ https://doi.org/10.1111/j.1558-5646.2007.00285.x

686 Bellwood, D.R., 2003. Origins and escalation of herbivory in fishes: a functional perspective.

687 Paleobiology 29, 71-83. https://doi.org/10.1666/0094-

688 8373(2003)029<0071:OAEOHI $>2.0 . \mathrm{CO} ; 2$

689 Bellwood, D.R., 1996. The Eocene fishes of Monte Bolca: The earliest coral reef fish 690 assemblage. Coral Reefs 15. https://doi.org/10.1007/BF01626074

691 Bermingham, E., McCafferty, S.S., Martin, A.P., 1997. Fish biogeography and molecular clocks:

692 Perspectives from the Panamanian Isthmus, in: Kocher, T.D., Stepien, C.A. (Eds.), 693 Molecular Systematics of Fishes. Academic Press, San Diego, CA, p. 314.

694 Bertrand, J.A., Borsa, P., Chen, W.-J., 2017. Phylogeography of the sergeants Abudefduf 695 sexfasciatus and A. vaigiensis reveals complex introgression patterns between two 696 697 widespread and sympatric Indo-West Pacific reef fishes. Mol. Ecol. 26, 2527-2542. https://doi.org/10.1111/mec.14044 
698 Blumenstiel, B., Cibulskis, K., Fisher, S., DeFelice, M., Barry, A., Fennell, T., Abreu, J., Minie,

699 B., Costello, M., Young, G., Maquire, J., Kernytsky, A., Melnikov, A., Rogov, P.,

700 Gnirke, A., Gabriel, S., 2001. Targeted Exon Sequencing by In-Solution Hybrid

701 Selection, in: Current Protocols in Human Genetics. John Wiley \& Sons, Inc.

702 https://doi.org/10.1002/0471142905.hg1804s66

703

Bohonak, A.J., 1999. Dispersal, gene flow, and population structure. Q. Rev. Biol. 74, 21-45.

704 https://doi.org/10.1086/392950

705

Bolger, A.M., Lohse, M., Usadel, B., 2014. Trimmomatic: A flexible trimmer for Illumina Sequence Data. Bioinformatics. https://doi.org/10.1093/bioinformatics/btu170

Bouckaert, R., Heled, J., Kühnert, D., Vaughan, T., Wu, C.-H., Xie, D., Suchard, M.A., Rambaut, A., Drummond, A.J., 2014. BEAST 2: a software platform for Bayesian evolutionary analysis. PLoS Comput Biol 10, e1003537. https://doi.org/10.1371/journal.pcbi.1003537

711 Choat, J.H., klanten, O.S., Van Herwerden, L., Robertson, D.R., Clements, K.D., 2012. Patterns and processes in the evolutionary history of parrotfishes (Family Labridae). Biol. J. Linn. Soc. Lond. 107, 529-557. https://doi.org/10.1111/j.1095-8312.2012.01959.x

714 Clements, K.D., Alfaro, M.E., Fessler, J.L., Westneat, M.W., 2004. Relationships of the temperate Australasian labrid fish tribe Odacini (Perciformes; Teleostei). Mol. Phylogenet. Evol. 32, 575-587. https://doi.org/10.1016/j.ympev.2004.02.003

Coates, A.G., Obando, J.A., 1996. The geologic evolution of the Central American Isthmus.

718 Evolution and environment in tropical America 21-56.

719 Cooper, J.W., Smith, L.L., Westneat, M.W., 2009. Exploring the radiation of a diverse reef fish 720 family: Phylogenetics of the damselfishes (Pomacentridae), with new classifications 
721

722

723

724

725

726

727

728

729

730

731

732

733

734

735

736

737

738

739

740

741

742

743

based on molecular analyses of all genera. Mol. Phylogenet. Evol. 52, 1-16. https://doi.org/10.1016/j.ympev.2008.12.010

Cooper, W.J., Albertson, R.C., Jacob, R.E., Westneat, M.W., 2014. Re-description and reassignment of the damselfish Abudefduf luridus (Cuvier, 1830) using both traditional and geometric morphometric approaches. Copeia 2014, 473-480. https://doi.org/10.1643/CI-13-074

Cooper, W.J., Westneat, M.W., 2009. Form and function of damselfish skulls: rapid and repeated evolution into a limited number of trophic niches. BMC Evol. Bio. 9, 24. https://doi.org/10.1186/1471-2148-9-24

de Queiroz, A., 2002. Contingent predictability in evolution: Key traits and diversification. Syst. Biol. 51, 917-929. https://doi.org/10.1080/10635150290102627

Emery, A.R., 1973. Comparative ecology and functional osteology of fourteen species of damselfish (Pisces: Pomacentridae) at Alligator Reef, Florida Keys. Bull. Mar. Sci. 23, $649-770$.

Faircloth, B.C., 2014. phyluce: phylogenetic estimation from ultraconserved elementes.

Faircloth, B.C., 2013. llumiprocessor: a trimmomatic wrapper for parallel adapter and quality trimming.

Faircloth, B.C., McCormack, J.E., Crawford, N.G., Harvey, M.G., Brumfield, R.T., Glenn, T.C., 2012. Ultraconserved elements anchor thousands of genetic markers spanning multiple evolutionary timescales. Syst. Biol. https://doi.org/10.1093/sysbio/sys004

Faircloth, B.C., Sorenson, L., Santini, F., Alfaro, M.E., 2013. A phylogenomic perspective on the radiation of ray-finned fishes based upon targeted sequencing of ultraconserved elements (UCEs). PLoS ONE 8, e65923. https://doi.org/10.1371/journal.pone.0065923 
744 Feitoza, B.M., Rocha, L.A., Luiz-Júnior, O.J., Floeter, S.R., Gasparini, J.L., 2003. Reef fishes of

745 St. Paul's Rocks: new records and notes on biology and zoogeography. Aqua 7, 61-82.

746 Fischer, E.A., 1980. Speciation in the hamlets (Hypoplectrus: Serranidae): a continuing enigma.

747

748

749

750

751

752

753

754

755

756

757

758

759

760

761

762

763

764

765 Copeia 649-659.

Floeter, S.R., Bender, M.G., Siqueira, A.C., Cowman, P.F., 2018. Phylogenetic perspectives on reef fish functional traits. Biol. Rev. 93, 131-151. https://doi.org/10.1111/brv.12336

Frédérich, B., Sorenson, L., Santini, F., Slater, Alfaro, M.E., 2013. Iterative Ecological Radiation and Convergence during the Evolutionary History of Damselfishes (Pomacentridae). Am. Nat. 181, 94-113. https://doi.org/10.1086/668599

Gaither, M.R., Schultz, J.K., Bellwood, D.R., Pyle, R.L., DiBattista, J.D., Rocha, L.A., Bowen, B.W., 2014. Evolution of pygmy angelfishes: Recent divergences, introgression, and the usefulness of color in taxonomy. Mol. Phylogenet. Evol. 74, 38-47. https://doi.org/10.1016/j.ympev.2014.01.017

Gomon, M.F., Paxton, J.R., 1985. A revision of the Odacidae: a temperate Australian-New Zealand labroid fish family. Bishop Museum Press.

Gould, S.J., Raup, D.M., Sepkoski, J.J., Schopf, T.J., Simberloff, D.S., 1977. The shape of evolution: a comparison of real and random clades. Paleobiology 3, 23-40. https://doi.org/10.1017/S009483730000508X

Hensley, D.A., 1978. Revision of the Indo-West Pacific Species of Abudefduf(Pisces: Pomacentridae) (Ph. D.). University of South Florida, Tampa, Florida USA.

Hensley, D.A., Randall, J.E., 1983. A new species of Abudefduf(Pisces: Pomacentridae) from the east coast of South Africa. Bishop Museum Press. 
766 Holt BG, Emerson BC, Newton J, Gage MJG, Côté IM, 2008. Stable isotope analysis of the

767 Hypoplectrus species complex reveals no evidence for dietary niche divergence. Mar.

768 Ecol. Prog. Ser. 357, 283-289. https://doi.org/10.3354/meps07339

769 Hunter, J.R., Mitchell, C.T., 1967. Association of fishes with flotsam in the offshore waters of

$770 \quad$ Central America. Fish. Bull. 66, 13-29.

771 Jacobs, D.K., Haney, T.A., Louie, K.D., 2004. Genes, diversity, and geologic process on the

772 Pacific coast. Annu. Rev. Earth Planet. Sci. 32, 601-652.

773 https://doi.org/10.1146/annurev.earth.32.092203.122436

774

775

776

777

778

779

780

781

782

783

784

785

786

787

788

Jokiel, P.L., 1990. Long-distance dispersal by rafting: reemergence of an old hypothesis. Endeavour 14, 66-73. https://doi.org/10.1016/0160-9327(90)90074-2

Jordan, D.S., 1908. The law of geminate species. Am. Nat. 42, 73-80. https://doi.org/10.1086/278905

Katoh, K., Misawa, K., Kuma, K., Miyata, T., 2002. MAFFT: a novel method for rapid multiple sequence alignment based on fast Fourier transform. Nucleic Acids Res. 30, 3059-3066. https://doi.org/10.1093/nar/gkf436

Khait, R., Obolski, U., Hadany, L., Genin, A., 2013. Food selectivity and diet switch can explain the slow feeding of herbivorous coral-reef fishes during the morning. PLoS One 8, e82391. https://doi.org/10.1371/journal.pone.0082391

Kimura, M., Morii, Y., Kuno, T., Nishida, H., Yoshimura, H., Akishige, Y., Senta, T., 1998. Flotsam ichthyofauna in the tropical waters of the West Pacific Ocean. Bulletin of the Faculty of Fisheries-Nagasaki University (Japan).

Kubo, T., Iwasa, Y., 1995. Inferring the rates of branching and extinction from molecular phylogenies. Evolution 49, 694-704. https://doi.org/10.1111/j.1558-5646.1995.tb02306.x 
789 Lanfear, R., Calcott, B., Ho, S.Y.W., Guindon, S., 2012. PartitionFinder: Combined Selection of

790 Partitioning Schemes and Substitution Models for Phylogenetic Analyses. Mol. Biol.

$791 \quad$ Evol. 29, 1695-1701. https://doi.org/10.1093/molbev/mss020

792 Lanfear, R., Calcott, B., Kainer, D., Mayer, C., Stamatakis, A., 2014. Selecting optimal

793 partitioning schemes for phylogenomic datasets. BMC Evol. Bio. 14, 1-14.

794 https://doi.org/10.1186/1471-2148-14-82

795 Leray, M., Beldade, R., Holbrook, S.J., Schmitt, R.J., Planes, S., Bernardi, G., 2010. Allopatric

796

797

divergence and speciation in coral reef fish: The three-spot Dascyllus, Dascyllus

trimaculatus, species complex. Evolution 64, 1218-1230. https://doi.org/10.1111/j.1558-

798 5646.2009.00917.x

799

Lessios, H.A., Allen, G.R., Wellington, G.M., Bermingham, E., 1995. Genetic and

800 morphological evidence that the Eastern Pacific damselfish Abudefduf declivifrons is

801

802 distinct from A. concolor (Pomacentridae). Copeia 1995, 277-288. https://doi.org/10.2307/1446891

803 Lester, S.E., Ruttenberg, B.I., 2005. The relationship between pelagic larval duration and range 804 size in tropical reef fishes: a synthetic analysis. Proc. Biol. Sci. 272, 585.

805 https://doi.org/10.1098/rspb.2004.2985

806 Lester, S.E., Ruttenberg, B.I., Gaines, S.D., Kinlan, B.P., 2007. The relationship between

807 dispersal ability and geographic range size. Ecol. Lett. 10, 745-758.

$808 \quad$ https://doi.org/10.1111/j.1461-0248.2007.01070.x

809 Lobato, F.L., Barneche, D.R., Siqueira, A.C., Liedke, A.M.R., Lindner, A., Pie, M.R., Bellwood,

810 D.R., Floeter, S.R., 2014. Diet and diversification in the evolution of coral reef fishes.

811 PLOS ONE 9, e102094. https://doi.org/10.1371/journal.pone.0102094 
812 Ludt, W.B., Rocha, L.A., 2015. Shifting seas: the impacts of Pleistocene sea-level fluctuations

813 on the evolution of tropical marine taxa. J. Biogeogr. 42, 25-38.

814 https://doi.org/10.1111/jbi.12416

815 Luiz, O.J., Allen, A.P., Robertson, D.R., Floeter, S.R., Kulbicki, M., Vigliola, L., Becheler, R., 816 Madin, J.S., 2013. Adult and larval traits as determinants of geographic range size among 817 tropical reef fishes. P. Natl. Acad. Sci. USA. 110, 16498-16502.

818 https://doi.org/10.1073/pnas. 1304074110

819 Luiz, O.J., Madin, J.S., Robertson, D.R., Rocha, L.A., Wirtz, P., Floeter, S.R., 2012. Ecological 820 traits influencing range expansion across large oceanic dispersal barriers: insights from 821 tropical Atlantic reef fishes. Pro. R. Soc. B. Biol. Sci. 279, 1033.

822 https://doi.org/10.1098/rspb.2011.1525

823 Marko, P.B., 2005. Fossil calibration of molecular clocks and the divergence times of geminate 824 species pairs separated by the Isthmus of Panama. Mol. Biol. Evol. 19, 2005-2012. 825 https://doi.org/10.1093/oxfordjournals.molbev.a004024

826 Masuda, H., Allen, G.R., 1993. Meeresfische der Welt - Groß-Indopazifische Region. Tetra 827 Verlag, Herrenteich, Melle.

828 McCafferty, S., Bermingham, E., Quenouille, B., Planes, S., Hoelzer, G., Asoh, K., 2002.

829 Historical biogeography and molecular systematics of the Indo-Pacific genus Dascyllus 830 (Teleostei: Pomacentridae). Mol. Ecol. 11, 1377-1392. https://doi.org/10.1046/j.1365294X.2002.01533.x

832 Mccartney, M.A., Acevedo, J., Heredia, C., Rico, C., Quenoville, B., Bermingham, E., 833 Mcmillan, W.O., 2003. Genetic mosaic in a marine species flock. Mol. Ecol. 12, 29632973. https://doi.org/10.1046/j.1365-294X.2003.01946.x 
835 McMillan, W.O., Palumbi, S.R., 1995. Concordant evolutionary patterns among Indo-West

836 Pacific butterflyfishes. Proc. R. Soc. Lond. B. Biol. Sci. 260, 229.

837 https://doi.org/10.1098/rspb.1995.0085

838 McMillan, W.O., Weigt, L.A., Palumbi, S.R., 1999. Color pattern evolution, assortative mating, 839 and genetic differentiation in brightly colored butterflyfishes (Chaetodontidae). Evolution $840 \quad 53,247-260$. https://doi.org/10.1111/j.1558-5646.1999.tb05350.x

841 Miller, K.G., 2009. Sea Level Change, Last 250 Million Years, in: Gornitz, V. (Ed.),

842 Encyclopedia of Paleoclimatology and Ancient Environments. Springer Netherlands,

843 Dordrecht, pp. 879-887. https://doi.org/10.1007/978-1-4020-4411-3_206

844 Moore, B.R., Höhna, S., May, M.R., Rannala, B., Huelsenbeck, J.P., 2016. Critically evaluating 845 the theory and performance of Bayesian analysis of macroevolutionary mixtures. Proc.

846 Natl. Acad. Sci. USA 113, 9569. https://doi.org/10.1073/pnas.1518659113

847 Nakata, H., Takeuchi, H., Hirano, T., 1988. A field experiment with drifting hoop nets to collect 848 the small fish gathering around drift algae. Bulletin of the Japanese Society of Scientific $849 \quad$ Fisheries (Japan).

850 O’Dea, A., Lessios, H.A., Coates, A.G., Eytan, R.I., Restrepo-Moreno, S.A., Cione, A.L., 851 Collins, L.S., de Queiroz, A., Farris, D.W., Norris, R.D., Stallard, R.F., Woodburne, 852 M.O., Aguilera, O., Aubry, M.-P., Berggren, W.A., Budd, A.F., Cozzuol, M.A., Coppard, 853 S.E., Duque-Caro, H., Finnegan, S., Gasparini, G.M., Grossman, E.L., Johnson, K.G., 854 Keigwin, L.D., Knowlton, N., Leigh, E.G., Leonard-Pingel, J.S., Marko, P.B., Pyenson, 855 N.D., Rachello-Dolmen, P.G., Soibelzon, E., Soibelzon, L., Todd, J.A., Vermeij, G.J., 856 Jackson, J.B.C., 2016. Formation of the Isthmus of Panama. Sci. Adv. 2.

857 https://doi.org/10.1126/sciadv.1600883 
858 Okada, Y., Ikeda, H., 1939. Notes on the fishes of the Ryu-Kyu Islands. IV. The damsel fish,

859 Pomacentridae, collected in 1938. Transactions of the Biogeographic Society of Japan,

860 Trans. Biogeogr. Soc. Japan. 3, 159-206.

861 Piñeros, V.J., Gutiérrez-Rodríguez, C., 2017. Population genetic structure and connectivity in the

862 widespread coral-reef fish Abudefduf saxatilis: the role of historic and contemporary

863 factors. Coral Reefs. https://doi.org/10.1007/s00338-017-1579-4

864 Puebla, O., Bermingham, E., Guichard, F., 2012. Pairing dynamics and the origin of species.

865 Proc. R. Soc. Lond. B. Biol. Sci. 279, 1085-1092. https://doi.org/10.1098/rspb.2011.1549

866 Puebla, O., Bermingham, E., Guichard, F., Whiteman, E., 2007. Colour pattern as a single trait

867 driving speciation in Hypoplectrus coral reef fishes? Proc. Biol. Sci. 274, 1265.

868 https://doi.org/10.1098/rspb.2006.0435

869 Puebla, O., Bermingham, E., McMillan, W.O., 2014. Genomic atolls of differentiation in coral

870 reef fishes (Hypoplectrus spp., Serranidae). Mol. Ecol. 23, 5291-5303.

871 https://doi.org/10.1111/mec.12926

872 Quenouille, B., Bermingham, E., Planes, S., 2004. Molecular systematics of the damselfishes

873 (Teleostei: Pomacentridae): Bayesian phylogenetic analyses of mitochondrial and nuclear

874 DNA sequences. Mol. Phylogenet. Evol. 31, 66-88. https://doi.org/10.1016/S1055-

$875 \quad 7903(03) 00278-1$

876 Rabosky, D.L., Grundler, M., Anderson, C., Shi, J.J., Brown, J.W., Huang, H., Larson, J.G.,

877 2014. BAMMtools: an R package for the analysis of evolutionary dynamics on

878 phylogenetic trees. Methods Ecol. Evol. 5, 701-707. https://doi.org/10.1111/2041-

$879210 X .12199$ 
880 Rabosky, D.L., Mitchell, J.S., Chang, J., 2017. Is BAMM Flawed? Theoretical and practical 881 concerns in the analysis of multi-rate diversification models. Syst. Biol. 66, 477-498. 882 https://doi.org/10.1093/sysbio/syx037

883 Randall, J.E., 2007. Reef and shore fishes of the Hawaiian Islands. Sea Grant College Program, $884 \quad$ University of Hawai' $i$.

885 Randall, J.E., 1967. Food habits of reef fishes of the West Indies. Institute of Marine Sciences, $886 \quad$ University of Miami Coral Gables.

887 Randall, J.E., Earle, J.L., 1999. Abudefduf conformis and Plectroglyphidodon sagmarius, two 888 new damselfishes (Pomacentridae) from the Marquesas Islands. Cybium 23, 333-343. 889 Raup, D.M., Gould, S.J., Schopf, T.J., Simberloff, D.S., 1973. Stochastic models of phylogeny 890 and the evolution of diversity. J. Geol. 81, 525-542. https://doi.org/10.1086/627905

891 Sale, P.F., 1980. The ecology of fishes on coral reefs. Oceanogr. Mar. Biol. Ann. Rev. 18, $367-$ 892 421.

893 Slatkin, M., 1987. Gene flow and the geographic structure of natural populations. Science 236, 894 787. https://doi.org/10.1126/science.3576198

895 Slowinski, J.B., 1990. Probabilities of n-trees under two models: a demonstration that 896 asymmetrical interior nodes are not improbable. Syst. Zool. 39, 89-94.

897 https://doi.org/10.2307/2992212

898 Stamatakis, A., 2014. RAxML version 8: a tool for phylogenetic analysis and post-analysis of $899 \quad$ large phylogenies. Bioinformatics 30, 1312-1313.

900 https://doi.org/10.1093/bioinformatics/btu033 
901 Tavera, J., Acero P., A., Wainwright, P.C., 2018. Multilocus phylogeny, divergence times, and a 902 major role for the benthic-to-pelagic axis in the diversification of grunts (Haemulidae).

903 Mol. Phylogenet. Evol. 121, 212-223. https://doi.org/10.1016/j.ympev.2017.12.032

904 Whiteman, E.A., Côté, I.M., Reynolds, J.D., 2007. Ecological differences between hamlet

905 (Hypoplectrus: Serranidae) colour morphs: between-morph variation in diet. J. Fish Biol.

906 71, 235-244. https://doi.org/10.1111/j.1095-8649.2007.01485.x

907 Whitney, J.L., Bowen, B.W., Karl, S.A., 2018. Flickers of speciation: Sympatric colour morphs

908 of the arc-eye hawkfish, Paracirrhites arcatus, reveal key elements of divergence with

909 gene flow. Mol. Ecol. 27, 1479-1493. https://doi.org/10.1111/mec.14527

910 Wibowo, K., Toda, M., Motomura, H., 2017. Validity of Abudefduf caudobimaculatus Okada

911 and Ikeda 1939 and synonymies of Abudefduf vaigiensis (Quoy and Gaimard 1825)

912 (Perciformes: Pomacentridae). Ichthyol. Res. https://doi.org/10.1007/s10228-017-0594-3

913 Zerbino, D.R., Birney, E., 2008. Velvet: Algorithms for de novo short read assembly using de

914 Bruijn graphs. Genome Res. 18, 821-829. https://doi.org/10.1101/gr.074492.107

915 


\section{Figure $\mathbf{1}$ (on next page)}

Maximum likelihood phylogenetic tree of Abudefduf

A maximum likelihood phylogenetic tree of Abudefduf generated from partitioned analysis of 361 ultraconserved element (UCE) loci. An optimal partitioning strategy was implemented (Lanfear et al., 2014, 2012) . Each partition was modeled under the General Time Reversible (GTR) model of sequence evolution with Gamma distributed rate variation (Г). Bootstrap support values are indicated with an asterisk $(*)$ if equal to 100 . The three lineages of Abudefduf are indicated (Clade A, B and C). Planktivorous lineages are highlighted and named in red with benthivorous lineages highlighted and named in blue. The tree is rooted by pomacentrid outgroups of the genera Chromis and Similiparma. The branch leading to an undescribed species, $A$. cf. vaigiensis, is colored gray. Appended to each leaf in the tree is the approximate geographic location of the sequenced individual using these abbreviations: $E A=$ East Atlantic, WA $=$ West Atlantic, $E P=$ East Pacific, $C P=$ Central Pacific, $W P=$ West Pacific, EIO = East Indian Ocean, and WIO = West Indian Ocean. Individual identifiers are appended to sample names in Supplemental Figure S1. Photo credits: A. hoefleri S. Floeter, A. saxatilis DRR, A. troschelii GRA, A. conformis J. Randall, $A$. vaigiensis GRA, $A$. abdominalis GRA, A. sparoides GRA, A. sexfasciatus J. Greenfield (CC BY), A. natalensis J. Randall, $A$. whitleyi GRA, A. bengalensis G. Edgar (CC BY), A. lorenzi GRA, A. margariteus GRA, A. cf. vaigiensis J. Earle, $A$. notatus GRA, $A$. septemfasciatus GRA, $A$. sordidus GRA, $A$. taurus DRR, A. concolor GRA, $A$. declivifrons GRA. 


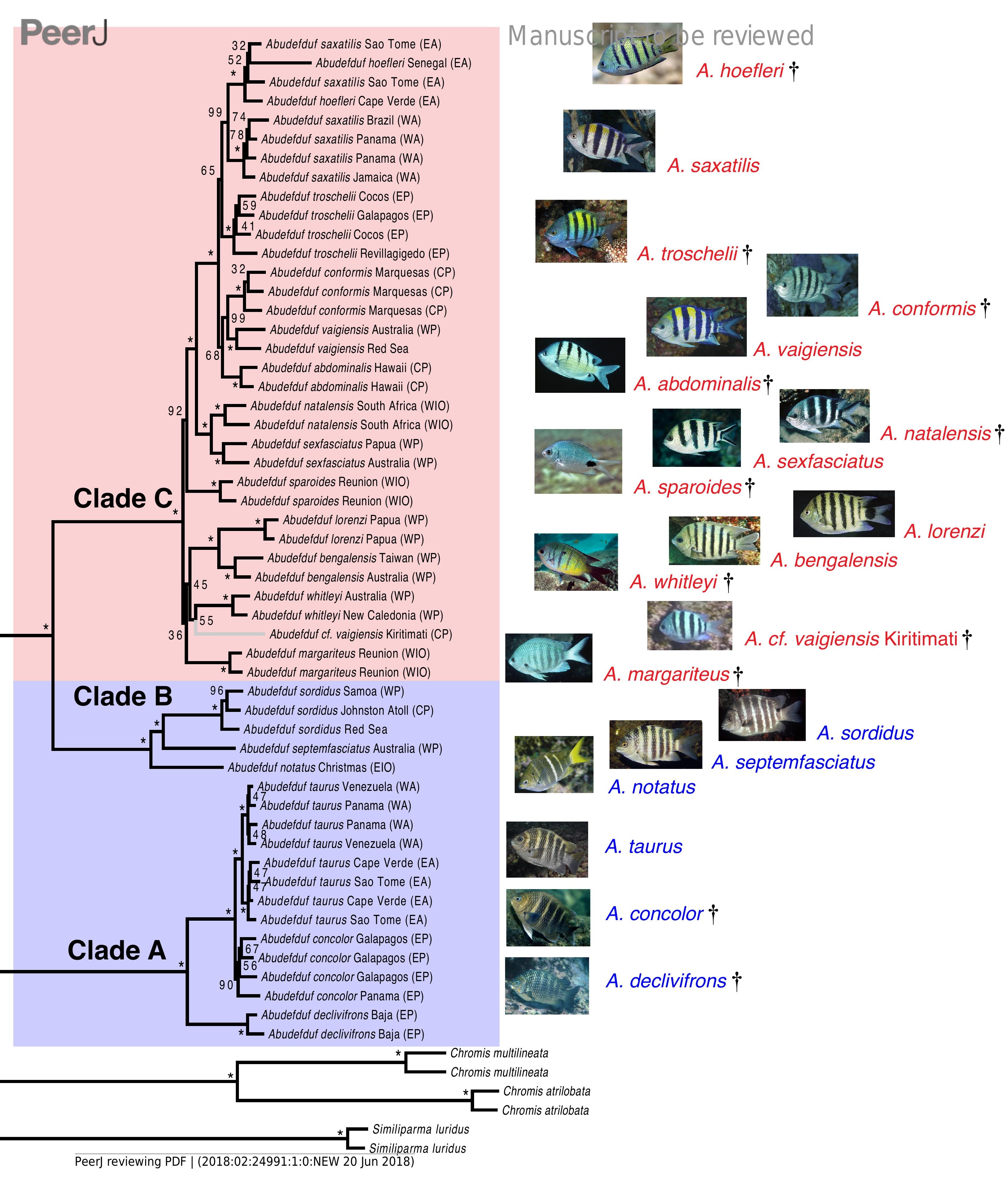




\section{Figure 2 (on next page)}

Time-calibrated phylogenetic tree of Abudefduf.

A time-calibrated phylogenetic tree of Abudefduf generated from 137 ultraconserved element (UCE) loci modeled under a single partition with the General Time Reversible (GTR) model with Gamma distributed rate variation $(\Gamma)$. Fossil-calibrated nodes are indicated by black triangles and are described in Supplemental Table S2. Posterior support at nodes is 1.00 unless otherwise indicated. Blue bars indicate $95 \%$ highest posterior density. The major trophic guilds are indicated by shading of red for planktivores and blue for benthivores. Regional endemics are indicated by a dagger (†). Invidual samples included in this analysis are indicated in Supplemental Table S1. Vertical lines indicate 25 million year time divisions with 10 million years and 3 million years also indicated. Appended to each leaf in the tree is the approximate geographic location of the sequenced individual using these abbreviations: $\mathrm{EA}=$ East Atlantic, $\mathrm{WA}=$ West Atlantic, $\mathrm{EP}=$ East Pacific, $\mathrm{CP}=$ Central Pacific, WP $=$ West Pacific, EIO = East Indian Ocean, and WIO = West Indian Ocean. 


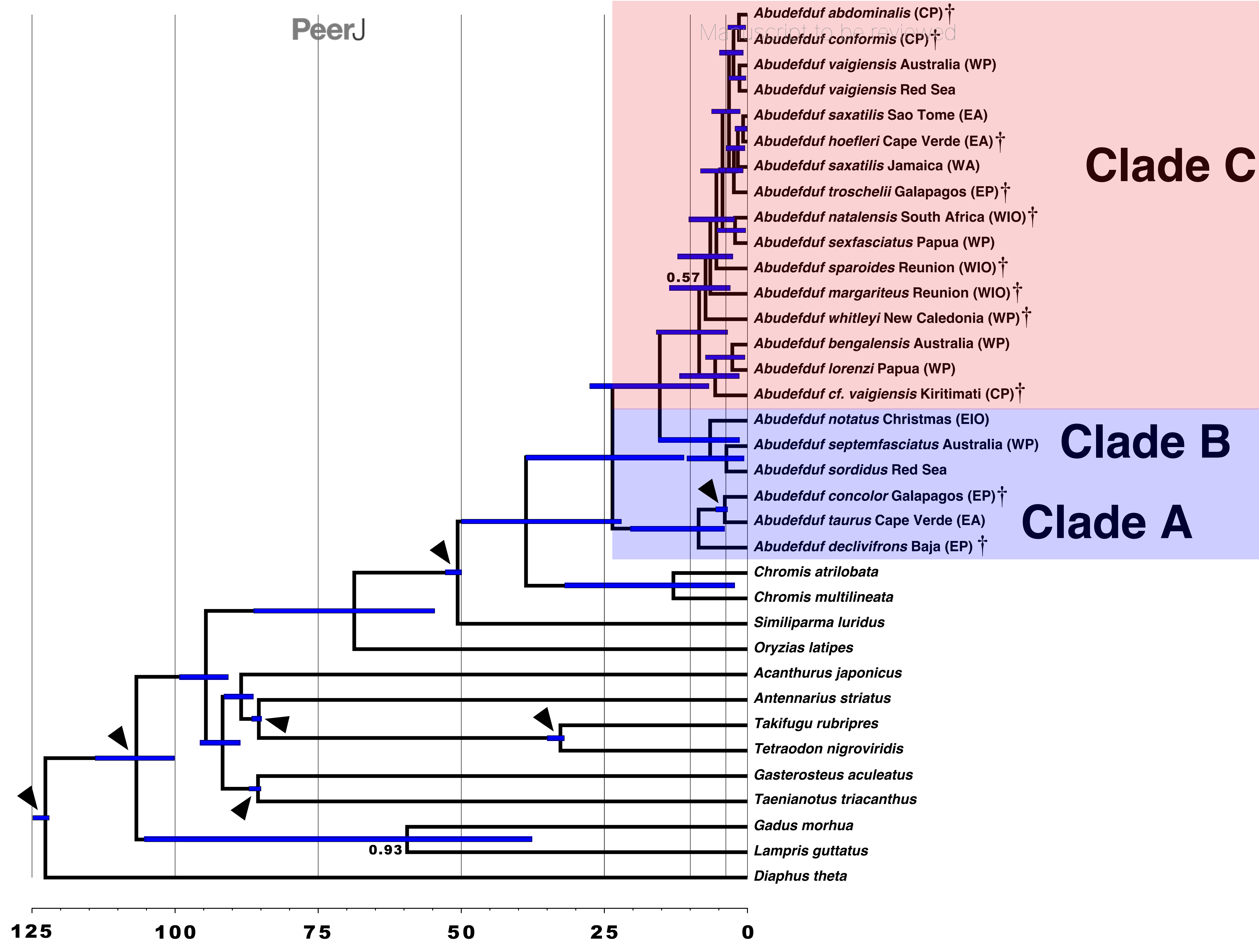


Figure 3 (on next page)

Phylogenetic relationships of Abudefduf saxatilis and A. hoefleri.

Phylogenetic relationships of Abudefduf saxatilis and $A$. hoefleri samples sequenced in this study rooted by $A$. troschelii. A maximum likelihood tree was generated by optimal partitioning (Lanfear et al., 2014, 2012) with each partition modeled with the General Time Reversible (GTR) model of sequence evolution and Gamma distributed rate variation (Г). Values at nodes are bootstrap support values. Collection sites of samples are indicated after names and the general geographic area of collection indicated. 
PeverJ A. saxatilis STRI-x-9898 (Jamaiga)

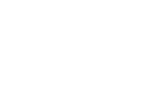

A. saxatilis STRI-x-10000 (Panama)

West Atlantic

A. saxatilis STRI-x-9897 (Jamaica)

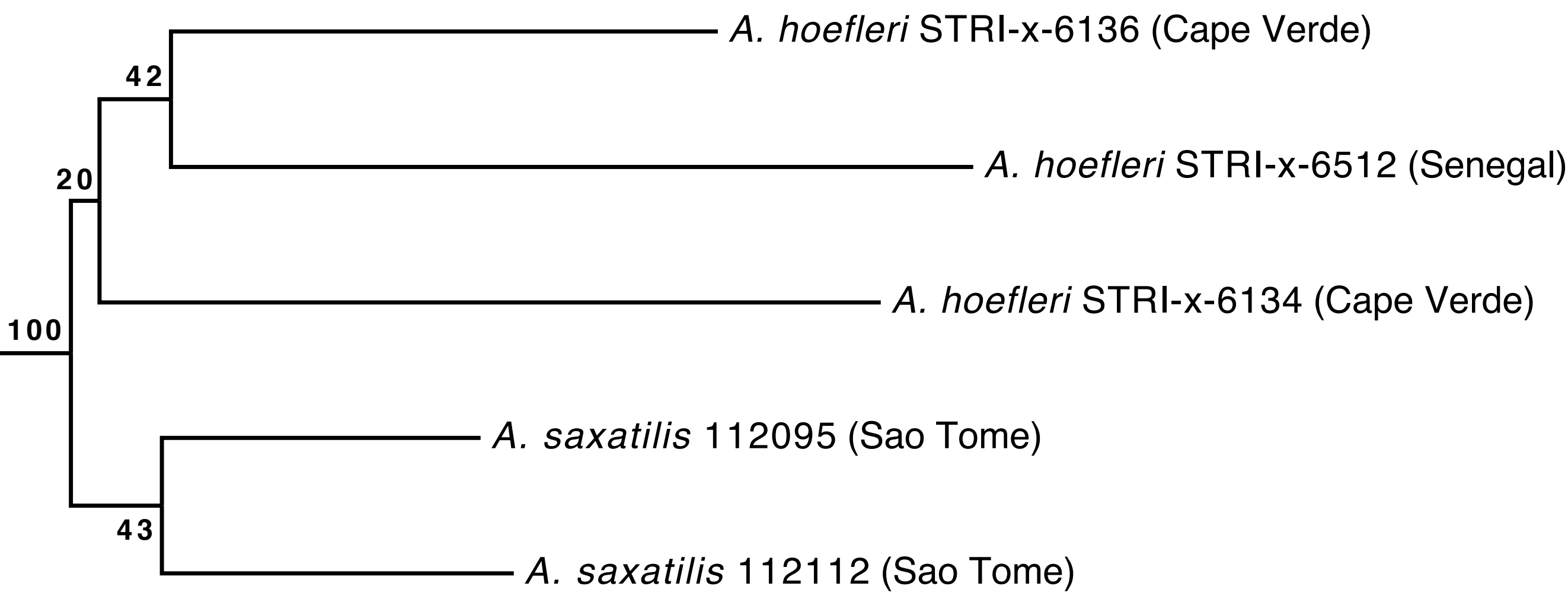

East Atlantic

A. troschelii STRI-x-1349 (Cocos) 